Cite as: Food Oxidants and Antioxidants Food Oxidants and Antioxidants: Chemical, Biological, and Functional Properties (Cap.16): 465-488 (2013), CRC Press, isbn: 9781439882412, http://hdl.handle.net/10261/109444

\title{
Case studies on selected natural food antioxidants
}

Miguel Herrero, José A. Mendiola, Alejandro Cifuentes and Elena Ibáñez

Institute of Food Science Research - CIAL (CSIC-UAM), Nicolas Cabrera 9, Campus de

Cantoblanco, 28049 - Madrid, Spain

Corresponding author: E. Ibáñez (elena@ifi.csic.es)

TEL: +34910 017956

FAX: +34910017905 
Cite as: Food Oxidants and Antioxidants Food Oxidants and Antioxidants: Chemical, Biological, and Functional Properties (Cap.16): 465-488 (2013), CRC Press, isbn: 9781439882412, http://hdl.handle.net/10261/109444

\section{TABLE OF CONTENTS.}

\section{1.- INTRODUCTION}

\section{2.- NOVEL AND GREEN EXTRACTION METHODS}

\subsection{Supercritical Fluid Extraction (SFE)}

2.2. Pressurized Liquid Extraction (PLE).

2.3. Subcritical Water Extraction (SWE).

2.4. Instrumentation for Compressed Fluids Extraction.

2.5. Other green extraction methods: Microwave and Ultrasound Assisted Extraction.

3.- CASE STUDY 1: ROSEMARY ANTIOXIDANTS.

\section{4.- CASE STUDY 2: MICROALGAL ANTIOXIDANTS-CAROTENOIDS}

4.1. Dunaliella salina.

4.2. Haematococcus pluvialis.

\section{CONCLUSIONS}

6.- REFERENCES 
Cite as: Food Oxidants and Antioxidants Food Oxidants and Antioxidants: Chemical, Biological, and Functional Properties (Cap.16): 465-488 (2013), CRC Press, isbn: 9781439882412, http://hdl.handle.net/10261/109444

\section{ABSTRACT}

In this chapter, a broad description of several case studies related to common antioxidants found in food-related products is presented. In this regard, special attention is put on the novel advanced environmentally-friendly extraction methods nowadays employed to extract and purify those potent antioxidants from natural matrices. A brief description of these extraction processes is provided together with some of the instrumentation needed. Besides, the studies carried out so far in two promising natural sources are described. Among them, rosemary (Rosmarinus officinalis) is proposed as model plant for the attainment of potent antioxidants while microalgae are suggested as potential alternative natural sources of antioxidants. In this sense, a detailed discussion on the available information concerning two of the best-known species in terms of antioxidant compounds, Dunaliella salina and Haematococcus pluvialis, is presented. 
Cite as: Food Oxidants and Antioxidants Food Oxidants and Antioxidants: Chemical, Biological, and Functional Properties (Cap.16): 465-488 (2013), CRC Press, isbn: 9781439882412, http://hdl.handle.net/10261/109444

\section{INTRODUCTION.}

As seen in previous chapters, antioxidants play an important role in food technology due to their usefulness against lipid oxidation and other oxidation processes. Moreover, plant antioxidants, derived from fruits and vegetables, have been associated to lower risks of coronary heart disease and cancer (Harris et al., 2002; Brigelius-Flohe et al., 2002). Many antioxidant compounds from natural origin have synergic effects with some endogenous enzymes such as superoxide dismutase or glutation peroxidase, antioxidants enhance their inhibitory effect against the degenerative processes of cells. For instance, some natural antioxidants such as tocopherols, have demonstrated higher activities than its synthetic forms (National Institute for Health, 2002; Brigelius-Flohe, 2002).

Therefore, the interest in finding natural sources of antioxidants is increasing and the search for new natural sources is also becoming more important. Main families of compounds with proved antioxidant activity are phenolic compounds, carotenoids and tocopherols, which are easily available in the vegetal kingdom. On the other hand, there is at present a huge interest in the potential use of marine natural sources to obtain these bioactives, mainly considering their huge diversity, in terms of number of different species that might be potentially used, their sometimes unique chemical structures and their ability to work as natural bioreactors potentiating the synthesis of valuable compounds depending on the cultivation conditions.

\section{NOVEL AND GREEN EXTRACTION METHODS.}

One important aspect that has to be closely considered, when searching for natural food antioxidants, is how these potential functional ingredients are obtained. In this regard, the need for appropriate, selective, cost-effective and environmentally-friendly extraction procedures to isolate these interesting compounds from natural sources has to be combined with the requirement of using food-grade solvents and processes. The use of new advanced 
Cite as: Food Oxidants and Antioxidants Food Oxidants and Antioxidants: Chemical, Biological, and Functional Properties (Cap.16): 465-488 (2013), CRC Press, isbn: 9781439882412, http://hdl.handle.net/10261/109444

extraction techniques, such as supercritical fluid extraction (SFE), pressurized liquid extraction (PLE), pressurized hot water extraction (PHWE), ultrasounds assisted extraction (UAE) and microwave assisted extraction (MAE), among others, can effectively overcome these problems.

\subsection{Supercritical Fluid Extraction (SFE)}

Supercritical fluid extraction (SFE) is based on the use of solvents at temperatures and pressures above their critical points. This technique has been already employed to extract a wide variety of interesting compounds from very different food-related materials (Mendiola et al., 2007).

SFE was first introduced in 1879 by Hannay and Hogarth. However, it was not until around 1960 that this extraction method started to be thoroughly investigated (Hosikian et al., 2010) as an alternative to conventional extraction methods, such as solid-liquid extraction (SLE) and liquid-liquid extraction (LLE), requiring large amounts of hazardous chemicals such as chlorinated solvents.

One of the most valuable characteristics of SFE is the highly reduced (often to zero) employment of toxic organic solvents. In this sense, carbon dioxide is the solvent most commonly used to extract antioxidant compounds from natural sources. In fact, $\mathrm{CO}_{2}$ has a series of interesting properties for antioxidants extraction: is cheap, its critical conditions are easily attainable $\left(30.9{ }^{\circ} \mathrm{C}\right.$ and 73.8 bar) and is an environmentally friendly solvent that, besides, is considered GRAS (Generally Recognized As Safe) for its use in the food industry. At supercritical conditions, $\mathrm{CO}_{2}$ has a high diffusivity while its solvent strength and density can be easily modified by tuning the temperature and pressure applied. Once the extraction procedure is finished, the depressurization of the system allows $\mathrm{CO}_{2}$ turning into gas and leaving the matrix while the compounds extracted from the matrix, and solubilized in the $\mathrm{CO}_{2}$ 
Cite as: Food Oxidants and Antioxidants Food Oxidants and Antioxidants: Chemical, Biological, and Functional Properties (Cap.16): 465-488 (2013), CRC Press, isbn: 9781439882412, http://hdl.handle.net/10261/109444

at high pressures, remained in the collector, therefore solvent-free extracts are obtained. These properties are responsible for the extended use of supercritical $\mathrm{CO}_{2}$ for extraction of bioactive compounds. The main drawback of $\mathrm{CO}_{2}$ is its low polarity, problem that can be overcome employing low amounts (1-10\%) of polar modifiers, also called co-solvents, to change the polarity of the supercritical fluid and to increase its solvating power towards the analyte of interest.

\subsection{Pressurized Liquid Extraction (PLE).}

In PLE, pressure is applied to allow the use of liquids at temperatures higher than their normal boiling point (Mendiola et al., 2007; Herrero et al., 2006a). PLE is also known as pressurized fluid extraction (PFE), enhanced solvent extraction (ESE), high-pressure solvent extraction (HPSE) or accelerated solvent extraction (ASE) (Nieto et al., 2010). This technique was described for the first time in 1996 (Richter et al., 1996).

PLE is broadly recognized as a green extraction technique, mainly due to its low organic solvent consumption. The combined use of high pressures and temperatures provides faster extraction processes that require small amount of solvents (e.g., 20 min using 10-50 $\mathrm{ml}$ of solvent in PLE can be compared with a traditional extraction procedure in which $10-48 \mathrm{~h}$ and up to $300 \mathrm{ml}$ are required). Usually, as long as the pressure is enough to keep the solvent in liquid or subcritical state, the effect of pressure changes is not very noticeable.

On the other hand, the increase on the extraction temperature can promote higher analytes solubility by increasing both, solubility and mass transfer rate. Besides, high temperatures decrease the viscosity and the surface tension of the solvents, helping to reach areas of the matrices more easily, thus improving the extraction rate. It could be said that instrumentation for PLE is quite simple, but nowadays there are just few commercial equipments available. 
Cite as: Food Oxidants and Antioxidants Food Oxidants and Antioxidants: Chemical, Biological, and Functional Properties (Cap.16): 465-488 (2013), CRC Press, isbn: 9781439882412, http://hdl.handle.net/10261/109444

\subsection{Subcritical Water Extraction (SWE).}

Water has many advantages in terms of versatility and environmental impact and can be used in extraction processes to isolate functional ingredients from different raw materials including plants and food wastes. Subcritical water extraction (SWE), also known as pressurized hot water extraction (PHWE), pressurized low polarity water (PLPW) extraction or superheated water extraction (SHWE) is a particular use of PLE with water as extracting solvent.

SWE is based in the use of water at temperatures above its atmospheric boiling point, while keeping it as liquid by applying pressure, just like in PLE for other solvents. Under this conditions, physical and chemical properties of water change dramatically, for instance, the dielectric constant of water decreases from around 80 at room temperature to around 33 at $200^{\circ} \mathrm{C}$, that is, close to a polar organic solvent such as ethanol (Turner and Ibañez, 2012; Herrero et al., 2005a). Moreover, the viscosity and surface tension are both reduced with increasing temperature, while diffusivity increased; altogether enhance the extraction process in terms of efficiency and speed. In addition, water's solubility parameter is also modified by temperature, thus favoring the solubility of different type of compounds and modifying its selectivity. Water is also the greenest solvent that can be used, perfectly complying with the rules of Green Chemistry and Green Engineering (Anastas et al., 2003).

When using pressurized hot water it must be taken into account that extraction conditions should be lower than supercritical point $\left(374^{\circ} \mathrm{C}, 218\right.$ bar). Supercritical or near-critical conditions can be used for supercritical water oxidation, hydrolysis and molecular transformations, such as biomass conversion; while in the subcritical region, extraction of antioxidant compounds can be performed.

\subsection{Instrumentation for Compressed Fluids Extraction.}


Cite as: Food Oxidants and Antioxidants Food Oxidants and Antioxidants: Chemical, Biological, and Functional Properties (Cap.16): 465-488 (2013), CRC Press, isbn: 9781439882412, http://hdl.handle.net/10261/109444

Figure 15.1 shows the scheme of an extraction device for compressed fluids. As expected, a single device can be used, with some modifications, to work either with supercritical fluids or with pressurized liquids such as water and ethanol.

\section{INSERT FIGURE 15.1 NEAR HERE}

A basic supercritical-fluid extractor consists of a tank of the mobile phase, usually $\mathrm{CO}_{2}$, a pump to pressurize the gas, an oven containing the extraction vessel, a restrictor to maintain the high pressure inside the system, and a trapping vessel. When a solvent able to modify the supercritical fluid solubility is needed, a second pump (high pressure liquid pump) can be included in the system, together with a mixing device (usually a coil) to heat the solvent mixture up to the needed temperature. After extraction, extracts are trapped by letting the solute-containing supercritical fluid decompress into an empty vial, through a solvent, or onto a solid or liquid material. An additional separator can be included in the system for fractional separation of the extracts at different precipitation conditions. Under these conditions, two different extracts can be obtained from each sample, each containing different compounds separated as a function of their solubility in the supercritical fluid at the conditions set in each separator.

Pressurized liquid's instrumentation is basically the same as for SFE but without the $\mathrm{CO}_{2}$ pump. It consists on a solvent reservoir coupled to a high pressure pump to introduce the solvent into the system, an oven, containing the extraction vessel and a restrictor or valve to keep the pressure inside the system. Extracts are collected in a vial placed at the end of the extraction system. In addition, the system can be equipped with a coolant device for rapid cooling of the resultant extract and with a $\mathrm{N}_{2}$ gas line to purge the extraction cell and the whole system after extraction. The system device is the same independently on the solvent 
Cite as: Food Oxidants and Antioxidants Food Oxidants and Antioxidants: Chemical, Biological, and Functional Properties (Cap.16): 465-488 (2013), CRC Press, isbn: 9781439882412, http://hdl.handle.net/10261/109444

used although some aspects should be considered depending on the maximum temperature used. For instance, working under supercritical conditions, maximum temperatures around $100^{\circ} \mathrm{C}$ are used while in PLE (or PHWE) temperatures are much higher (up to $200-250^{\circ} \mathrm{C}$ ). This will influence the material used to build the extraction cell and the device employed for pre-heating the solvent (and its placement in the system). For further information on how to build your own system in PHWE, readers are referred to Turner and Ibáñez (2012).

Extractions with compressed fluids can be done in dynamic, static, or combination of both. In a dynamic extraction, the fluid continuously flows through the sample in the extraction vessel and out the restrictor to the trapping vessel/vial. In static mode, the fluid circulates in a loop containing the extraction vessel for some period of time before being released through the restrictor to the trapping vessel. In the combined mode, a static extraction is performed for some period of time, followed by a dynamic extraction. Additionally, when working at high temperatures in PLE, dynamic operation may avoid, to some extent, thermal degradation of bioactive compounds since the liquid solvent flows continuously through the matrix at a certain flow rate therefore improving the efficiency of the extraction and avoiding the excessive heating of the sample.

\subsection{Other green extraction methods: Microwave and Ultrasound Assisted Extraction.}

Among green techniques for antioxidants' extraction, Ultrasounds Assisted Extraction (UAE) and Microwave Assisted Extraction (MAE) have an enormous potential, although they have not been much used for these purposes. Both techniques are fast, which is a key point to avoid degradation of labile compounds, use low amounts of solvents and are cost-effective. Both methods are very versatile due to the possibility of using several solvents of different polarities; in fact, both can couple extraction and reaction at the same time. 
Cite as: Food Oxidants and Antioxidants Food Oxidants and Antioxidants: Chemical, Biological, and Functional Properties (Cap.16): 465-488 (2013), CRC Press, isbn: 9781439882412, http://hdl.handle.net/10261/109444

UAE uses acoustic cavitation to cause disruption of cell walls, reduction of the particle size and enhancement of contact between the solvent and the target compounds. When a liquid is irradiated by ultrasound, micro-bubbles form, grow, and oscillate extremely fast, and eventually collapse powerfully if the acoustic pressure is high enough. These collapses, occurring near a solid surface, generate micro-jets and shock waves that result in cleaning, erosion, and fragmentation of the surface (Ötles, 2009).

MAE was first described in 1986 (Ganzler et al., 1986), it uses microwave radiation that causes motion of polar molecules and rotation of dipoles to heat solvents and to promote transfer of target compounds from the sample matrix into the solvent. In general, samples for MAE are homogenized and mixed with a solvent and the suspension irradiated at higher than $2000 \mathrm{MHz}$ for short periods of time. Heating is usually repeated several times with periods of cooling in between to prevent boiling. Techniques have also been developed using closedsystem microwave heating, the most used nowadays, which let the mixture of sample and solvent to increase the pressure due to the reaching of boiling point, therefore, the extraction takes place in similar condition as Pressurized Liquid Extraction (Ötles, 2009).

\section{CASE STUDY 1: ROSEMARY ANTIOXIDANTS.}

Rosemary (Rosmarinus officinalis L.) is a medicinal plant from the Order Lamiales, Family Lamiaceae, Genus Rosmarinus L. Rosemary leaves contain essential oil (1.0-2.5\%) which composition depends on the origin, chemotype and development stage of the plant at collection. The most characteristic compounds of the essential oil are: 1,8-cineol (20-50\%), $\alpha$ pinene (15-25\%), camphor (10-25\%), camphene (5-10\%), borneol (1-6\%), bornyl acetate (1$5 \%)$ and $\alpha$-terpineol $(12-24 \%)$. In the Mediterranean area there exist two main rosemary essential oils mainly differing in their content in 1,8-cineol: the one grown in Morocco and Tunisia, with a high level and the one grown in Spain, with a low content of this compound. 
Cite as: Food Oxidants and Antioxidants Food Oxidants and Antioxidants: Chemical, Biological, and Functional Properties (Cap.16): 465-488 (2013), CRC Press, isbn: 9781439882412, http://hdl.handle.net/10261/109444

Other important compounds found in Rosemary extracts are: phenolic diterpenes (carnosol and carnosic acid); polyphenols: cafeic and rosmarinic acid, flavonoids (apigenin, luteolin); triterpenes (ursolic acid). Essential oil and extracts composition will depend on the specie and the type of plant, and also on the growing conditions, the season and the preprocessing after collection. All these factors together with genetics, age and origin, will influence the organoleptic characteristics and the bioactivity of plant extracts.

Hidalgo et al. (1998) determined that changes in carnosic acid content in rosemary leaves were mainly due to seasonal and environmental factors such as leaf age, photoperiod and temperature during growing. In general, younger leaves and those grown in summer months (more temperature and sunshine) contained higher carnosic acid concentration. These results are in agreement with those of Celiktas et al. (2007) that studied the variability of the amounts of active constituents due to geographical locations growth and seasonal variations; these authors also found out that plants harvested in September possessed higher levels of active constituents. Nevertheless, other authors (Munné-Bosch et al., 2000), found out that the highest concentrations of carnosic acid were produced during winter and the lowest in summer due to the highest heat and light stress of the plant.

As for the influence on essential oil composition, numerous works have been published in this sense (Mizrahi y col., 1991; Chalchat y col., 1993; Boyle y col., 1991; Guillén y col., 1996). In terms of bioactivities, antioxidant capacity of rosemary plant was first reported in 1955 (Rac and Ostric-Matijasevic, 1955) being its composition completely known at present. In 1964 carnosol was isolated (Brieskorn et al., 1964) and antioxidant properties were attributed to this compound. Its structure together with carnosic acid, were confirmed in 1982 (Wu et al., 1982). Rosmanol, rosmarinic acid (Inatani et al., 1982), rosmadial (Inatani et al., 1983), epirosmanol, isorosmanol (Nakatani and Inatani, 1984), rosmaridiphenol (Houlihan et al., 1984) and rosmariquinone (Houlihan et al., 1985) were further identified. Flavonoids with 
Cite as: Food Oxidants and Antioxidants Food Oxidants and Antioxidants: Chemical, Biological, and Functional Properties (Cap.16): 465-488 (2013), CRC Press, isbn: 9781439882412, http://hdl.handle.net/10261/109444

antioxidant activity have also been reported (Okamura et al., 1994); the chemical structures of some of the most important antioxidant compounds in rosemary are shown in Figure 15.2.

The main compound responsible of the antioxidant activity is carnosic acid (Aruoma et al., 1992; Cuvelier et al., 1996), a phenolic diterpene which is also the most abundant compound in rosemary leaves. Carnosic acid is a lipophilic antioxidant able to neutralize oxygen, hydroxyl and peroxyl radicals, preventing the lipid oxidation and the damage in biological membranes (Aruoma et al., 1992; Haraguchi et al, 1995). The activity of carnosic acid against free radicals follows a mechanism similar to other known antioxidants such as $\alpha$-tocopherol and is due to the presence of two hydroxyl groups at orto position in the phenolic ring (positions C11 and C12, see Figure 15.2) (Richhelmer et al., 1999). Rosemary phenolic compounds act as primary antioxidants (Haraguchi et al., 1995; Basaga et al., 1997; Frankel et al., 1996) and have shown synergies with other antioxidants, for instance, $\alpha$-tocopherol (Wada and Fang, 1992; Hopia et al., 1996) and the enzymes glutation reductase and NADPHquinone reductase. Some authors attributed the demonstrated protective effects against lung, liver and stomach cancer in rats to these synergies with enzymes (Singletary and Rokusek, 1997).

\section{INSERT FIGURE 15.2 NEAR HERE}

Although carnosic acid is nowadays recognized as the main antioxidant compound in rosemary leaves, carnosol can sometimes be detected as the main compound (up to $90 \%$ ) coming from carnosic acid oxidation during the extraction process (Shwarz and Ternes, 1992). During degradation, carnosic acid can be enzymatically dehydrogenated to carnosol (Munne-Bosch et al., 2000), and further oxidized to rosmanol and isorosmanol due to free radicals attack (Luis, 1991; Luis et al., 1994). 
Cite as: Food Oxidants and Antioxidants Food Oxidants and Antioxidants: Chemical, Biological, and Functional Properties (Cap.16): 465-488 (2013), CRC Press, isbn: 9781439882412, http://hdl.handle.net/10261/109444

Therefore, is not only important the selection of the raw material but also the processing conditions used to obtain the bioactive extract. As mentioned in the introduction, there is a need in developing new extraction processes able to keep the original bioactive properties while improving the whole process in terms of cost-effectiveness, environmental impact and health safety. Therefore, not only food-grade solvents should be used (including GRAS approved solvents such as ethanol, water and carbon dioxide) but also sustainable processes providing a higher selectivity (extracting only the interesting compounds) and efficiency (extracting with high yields), at lower costs (economical and energy). In this case study, the techniques mentioned in the introduction (SFE, PLE, PHWE, UAE and MAE) will be discussed in regard to their contribution to the extraction of antioxidants from rosemary.

SFE has been widely studied for several authors to obtain highly active rosemary antioxidant extracts. For instance, Topal et al. (2008) demonstrated that the antioxidant activity of supercritical extracts of different Turkish plants (rosemary among them) were higher than those obtained by steam distillation. Better results in terms of antioxidant activity were also achieved when compared to liquid solvent sonication (Tena et al., 1997).

Supercritical processing conditions will depend on the target product/products to be extracted. For instance, research has been conducted to optimize dearomatization of rosemary extracts obtained by steam distillation and soxhlet extraction; extracts with good antioxidant activity and $90 \%$ deodorization were achieved under relatively mild conditions $\left(200 \mathrm{bar}, 60^{\circ} \mathrm{C}\right.$, pure $\mathrm{CO}_{2}$ ) (Lopez-Sebastian et a., 1998). Other authors reported 100 bar and $35^{\circ} \mathrm{C}$ as the best conditions to remove rosemary essential oil from crude extracts obtained using conventional processes (Hadolin et al., 2004). Sequential two-steps extraction has been used to divide rosemary oleoresin in two fractions with different antioxidant activities and essential oil composition (Ibañez et al., 1999). In this paper, authors reported not only the best conditions to obtain both fractions but also the effect of plant processing in the final composition of 
Cite as: Food Oxidants and Antioxidants Food Oxidants and Antioxidants: Chemical, Biological, and Functional Properties (Cap.16): 465-488 (2013), CRC Press, isbn: 9781439882412, http://hdl.handle.net/10261/109444

extracts. In this sense, conventional drying at ambient temperature in a ventilated place seems to be the best processing conditions. Different products were obtained under the following conditions: step 1: 100 bar, $40^{\circ} \mathrm{C}$, and essential oil fraction; step 2: 400 bar, $60^{\circ} \mathrm{C}$, and antioxidant fraction. Babobic et al., 2010, also studied the sequential extraction of rosemary in two different fractions, with similar results, and suggested the use of rosemary antioxidants as food additives to substitute synthetic antioxidants such as BHA (Babovic et al., 2010).

Similar results could be obtained working under fractional separation after supercritical extraction. This approach allows extracting a rosemary oleoresin that is further fractionated in two separators by stepwise decompression at different pressure and/or temperature conditions, leading to two different fractions with different antioxidant activities and composition. Señorans et al. (2000), studied the conditions to selectively recover one antioxidant fraction with almost no residual aroma in the first separator and an enriched essential oil fraction in the second separator; conditions leading to the best combination of extracts were as follows: extraction conditions: 350 bar, $50^{\circ} \mathrm{C}$, no modifier; fractionation conditions in separator 1: 200 bar, $50^{\circ} \mathrm{C}$; fractionation conditions in separator 2: atmospheric conditions. In a further study, the same authors studied both, fractionation and extraction yields together with carnosic acid extraction as a function of experimental conditions, and examined the correlation between carnosic acid and the antioxidant activity measured. Results obtained show that carnosic acid seemed to be the main compound responsible for the antioxidant activity of rosemary extracts but also some other compounds present in the extract may affect, positively or negatively, the antioxidant activity of the final extracts (Cavero et al., 2005).

In an attempt to scale up the SFE of rosemary antioxidants, Carvalho et. al., (2005) studied the kinetics of SFE in two different-scale extraction units and the fitting of the overall extraction curves (experimental values) to different mathematical models (Carvahlo et al., 2005); kinetic and model parameters were obtained and results showed that models of Goto, 
Cite as: Food Oxidants and Antioxidants Food Oxidants and Antioxidants: Chemical, Biological, and Functional Properties (Cap.16): 465-488 (2013), CRC Press, isbn: 9781439882412, http://hdl.handle.net/10261/109444

Sovová and Esquível provided with the best results and can be used for process design. Based on these results, Garcia-Risco et al. (2011), studied the kinetic behavior of supercritical rosemary extract at pilot scale (operated at 300 bar and $40^{\circ} \mathrm{C}$ with pure carbon dioxide) and the kinetics recovery of carnosic acid; although global extraction yield achieved was similar as in analytical or low-scale experiments, extraction time needed was higher; the authors suggested a slower kinetics at large scale due to the higher size of the solid particles used, which in turn make the process to be controlled by solute diffusion in the solid phase.

Antioxidant activity of rosemary extracts, together with other interesting bioactivities, has been studied under different supercritical conditions at different scales (analytical, pilot) by different authors. For instance, Leal et al. (2003) studied antioxidant, anticancer and antimycobacterial activities of different spices extracted under supercritical conditions, while Kuo et al., 2011 focused on the anti-inflammatory effect of both, rosemary extracts and isolated carnosic acid; authors demonstrated that at 345 bar and $80^{\circ} \mathrm{C}$, higher yields, total phenolics and individual concentration of bioactive phenolics were obtained (Kuo et al., 2011). Same results were obtained under the same extraction conditions in terms of antioxidant activity (Chang et al., 2008).

As largely mentioned in this case study, all the reports published up to now associated the strong antioxidant activity of rosemary extracts to the presence of phenolic diterpenes, such as carnosic acid and carnosol and, therefore, there is a strong interest in isolating and purifying these compounds from a natural source such as rosemary. Although fractional separation and/or two steps extraction can be considered as a first approach for concentrating the complex extracts in such important compounds, more sophisticated attempts have been made to truly isolate them using supercritical fluids. For instance, pioneer works of Ramirez et al., demonstrated the ability of supercritical fluid chromatography (SFC) to isolate antioxidant compounds from rosemary supercritical extracts at analytical scale on specially designed 
Cite as: Food Oxidants and Antioxidants Food Oxidants and Antioxidants: Chemical, Biological, and Functional Properties (Cap.16): 465-488 (2013), CRC Press, isbn: 9781439882412, http://hdl.handle.net/10261/109444

columns packed with coated particles and able to perform the expected separation using pure $\mathrm{CO}_{2}$ (Ramirez et al., 2004; Ramirez et al., 2005); these results were scaled up to a prep-SFC system with the columns build ad-hoc and the separation and collection conditions optimized (Ramirez et al., 2006; Ramirez et al., 2007); important enrichment of antioxidant fractions were obtained using this procedure.

In a new approach by Braida et al. (2008), a new extraction-adsorption-desorption procedure using supercritical $\mathrm{CO}_{2}$ as solvent was developed using as starting material a crude oleoresin obtained using organic solvents. In this new combination, different processes using supercritical $\mathrm{CO}_{2}$ were employed, as follows: first, a supercritical extraction of the oleoresin was carried out followed by an adsorption step with a commercial adsorbent (activated carbon); after adsorption, retained compounds were recovered in a desorption step under the same supercritical condition but using ethanol as co-solvent. Even if it was possible to increase carnosic acid concentration, it was only to a lower extent due to the presence of nonsoluble compounds. A scheme of the experimental set up used can be seen in Figure 15.3.

\section{INSERT FIGURE 15.3 NEAR HERE}

Visentin et al. (2011) suggested the isolation of carnosic acid from a high viscous oleoresin extracted with ethanol by using supercritical fluid antisolvent fractionation. Advantages of the process include the high concentrations in carnosic acid achieved and the possibility of carrying it out in a continuous or semi-continuous way, which can favor its scaling up at industrial level.

Different green processes, other than SFE, have been also studied to extract bioactives from rosemary leaves. In a recent contribution by Herrero et al. (2010), the performance of three different extraction procedures (PLE using water and ethanol as solvents, SFE using neat $\mathrm{CO}_{2}$ 
Cite as: Food Oxidants and Antioxidants Food Oxidants and Antioxidants: Chemical, Biological, and Functional Properties (Cap.16): 465-488 (2013), CRC Press, isbn: 9781439882412, http://hdl.handle.net/10261/109444

and supercritical $\mathrm{CO}_{2}$ modified with ethanol, and Water Extraction and Particle formation Online (WEPO)) towards the extraction of antioxidants from rosemary was studied. Different extraction conditions were tested including extraction temperature, time and pressure. PLE with both, water and ethanol, provided with the best results in terms of extraction yield and quality of the antioxidants extracted. Best conditions were achieved using ethanol at $200^{\circ} \mathrm{C}$ or water at $100^{\circ} \mathrm{C}$. The study confirmed the important effect of the extraction temperature on the selectivity of the process. Even if the WEPO process produced less extraction yield, under not optimized conditions, recent results obtained in our research group (data not shown) demonstrated the potential of this new on-line process in which subcritical water extraction is carried out in a dynamic mode, followed by a drying step, in which supercritical $\mathrm{CO}_{2}$ is mixed with the liquid extract and expanded into a precipitation chamber with a hot nitrogen current added (Ibáñez et al., 2009). Results obtained for SFE were similar as those previously mentioned.

Selectivity of hot water (or subcritical water) extraction towards extraction of antioxidants from rosemary was first reported by Ibañez et al. (2003). In this contribution, the effect of extraction temperature was studied for the first time to obtain extracts enriched in different polarity antioxidants. Results indicate the high selectivity of the subcritical water towards the most active compounds of rosemary such as carnosol, rosmanol, carnosic acid, methyl carnosate, and some flavonoids such as cirsimaritin and genkwanin. The antioxidant activity of the fractions obtained by extraction at different water temperatures was very high, with values comparable to those achieved by SFE of rosemary leaves. Antioxidants were measured by using LC-MS and CE alone (Crego et al., 2004) or in combination with MS (Herrero et al., 2005b). In a recent paper, authors demonstrated that no occurrence of Maillard reaction was observed in rosemary subcritical water extracts, even considering the high extraction temperatures (up to $200^{\circ} \mathrm{C}$ ) (Plaza et al., 2010). Although neoformation of antioxidants was 
Cite as: Food Oxidants and Antioxidants Food Oxidants and Antioxidants: Chemical, Biological, and Functional Properties (Cap.16): 465-488 (2013), CRC Press, isbn: 9781439882412, http://hdl.handle.net/10261/109444

observed in several natural raw materials extracted, mainly algae, no degradation of bioactive compounds neither formation of new antioxidants could be observed for rosemary at $200^{\circ} \mathrm{C}$.

Microwave assisted extraction (MAE) in form of solvent-free microwave extraction (SFME) has been also used to extract essential oil from rosemary leaves. In a recent paper, Okoh et al., 2011, demonstrated the antioxidant activity of this essential oil (Okoh et al., 2011) while Navarrete et al. (2011), used SFME to recover essential oil, previous to antioxidant extraction of the residue by S-L extraction with ethanol. After SFME, higher yields were obtained, mainly in carnosic acid and carnosol. This effect might be due to modifications in plant structure during treatment that lately favors the mass transfer of antioxidant compounds.

Few contributions can be found in the literature referring to the use of ultrasounds to improve antioxidant extraction from rosemary leaves. For instance, Albu et al. (2004) studied the effect of solvent, leaves' water content and temperature in carnosic acid yields, considering sonication as the technique to increase the extraction efficiency (Albu et al., 2004). Lately, the same authors studied the scaling up of the ultrasonic extraction process using ethanol or methanol as extracting solvents and determined that the use of ultrasound provided a more effective extraction at lower temperatures with less dependence on the extraction solvent employed and that scale up of the process was possible.

Other than in-vitro assays to assess the bioactivity of supercritical rosemary extracts, some authors have also studied their in-vivo effects in both, aged and diabetic rats. Extracts containing $20 \%$ of carnosic acid showed an improvement of the oxidative stress status in aged rats (Posadas et al., 2009) and differences in the metabolites found in control and treated diabetic rats. Moreover, these extracts showed a low acute toxicity, with oral lethal doses $\left(\mathrm{LD}_{50}\right)$ for male and female rats were greater than $2000 \mathrm{mg} / \mathrm{kg}$ of body weight (Anadon et al., 2008). 
Cite as: Food Oxidants and Antioxidants Food Oxidants and Antioxidants: Chemical, Biological, and Functional Properties (Cap.16): 465-488 (2013), CRC Press, isbn: 9781439882412, http://hdl.handle.net/10261/109444

These results demonstrated the possibilities of rosemary extracts enrich in phenolic diterpenes towards health enhancement. Nevertheless, more studies are needed to confirm these results and to further develop a functional ingredient able to act preventing or retarding some diseases associated to oxidative stress or even aging. Initial steps have been taken to develop formulations to improve digestion and bioavailability of rosemary supercritical extracts (Soler-Rivas et al., 2010).

Due to the above mentioned demonstrated biological activities of rosemary supercritical extracts, at present, supercritical extraction with carbon dioxide is one of the processes used at industrial scale to provide with high quality rosemary extracts. Companies such as Supercritical Fluid Technologies, Inc.; Natural Wisdom Holistic Beauty Ltd.; Gaia Herbs; Arkopharma, etc., are among those selling commercial rosemary extract obtained under supercritical conditions.

\section{CASE STUDY 2: MICROALGAL ANTIOXIDANTS-CAROTENOIDS.}

More than $60 \%$ of our planet is constituted by marine environment, which offers a wide array of applications in biotechnology. The use of "Blue biotechnology" is related to the application of molecular biological methods to marine and freshwater organisms. It involves the use of these organisms, and their derivatives. Among those organisms, microalgae, especially those from marine origin, remain to date largely unexplored, so they represent a unique opportunity to discover novel metabolites and to produce known metabolites at lower costs (Guedes et al., 2011). In fact, current scientific consensus holds that significant amounts of oxygen $\left(\mathrm{O}_{2}\right)$ first appeared in the Earth's atmosphere some 2.4 billion years ago due to the photosynthetic activity of blue-green algae, therefore marine microorganism were those who first developed antioxidant mechanism. 
Cite as: Food Oxidants and Antioxidants Food Oxidants and Antioxidants: Chemical, Biological, and Functional Properties (Cap.16): 465-488 (2013), CRC Press, isbn: 9781439882412, http://hdl.handle.net/10261/109444

As mentioned, the interest in finding natural sources of antioxidants is increasing and the search for new natural sources such as algae or microalgae is also becoming more important. Antioxidants can play a major role in food technology because of their usefulness against lipid oxidation. Moreover, plant antioxidants, derived from fruits and vegetables, have been associated to lower risks of coronary heart disease and cancer (Brigelius-Flohe et al., 2002). Natural antioxidants offer food, pharmaceutical, nutraceutical, and cosmetic manufacturers a "green" label, minimal regulatory interference with use, and the possibility of multiple actions that improve and extend food and pharmaceutical stabilization (Schaich, 2006). Determining antioxidant capacity has become a very active research topic, and a plethora of antioxidant assay methods are currently in use.

Carotenoids are prominent for their distribution, structural diversity and various functions. More than 600 different naturally occurring carotenoids are now known, excluding cis and trans isomers, all derived from the same basic C40 isoprenoid skeleton with some modifications such as cyclization, substitution, elimination, addition, and rearrangement (Schubert et al., 2006). The beneficial effects of carotenoids have been well documented from numerous clinical and epidemiological studies in various populations, despite in certain circumstances they could act as prooxidants (Palozza et al., 2008). Carotenoids play a key role in oxygenic photosynthesis, as accessory pigments for harvesting light or as structural molecules that stabilize protein folding in the photosynthetic apparatus.

Green microalgae Dunaliella salina and Haematococcus pluvialis are among the most studied microalgae for their carotenoid content. Both microalgae have something important in common, they produce carotenoids in large amount when they grow under stress conditions.

\subsection{Dunaliella salina.}


Cite as: Food Oxidants and Antioxidants Food Oxidants and Antioxidants: Chemical, Biological, and Functional Properties (Cap.16): 465-488 (2013), CRC Press, isbn: 9781439882412, http://hdl.handle.net/10261/109444

The genus Dunaliella is one of the most reported for the production of carotenoids and belongs to the group of halotolerant unicellular microalgae. This microalga accumulates large amounts of $\beta$-carotene in chloroplasts. In average, it can produce $400 \mathrm{mg}$ of $\beta$-carotene per $\mathrm{m}^{2}$ per day, when cultured in open tanks; meaning $10-14 \%$ of the dry weight (Ribeiro et al., 2011; Dufossé et al., 2005). Carotenoids from Dunaliella salina are produced on a commercial scale in open ponds in e.g. Australia and Israel. These systems seem to have reached their technical limits in the 90's. High $\mathrm{CO}_{2}$ consumption with low efficiency, impractical control of some environmental factors, contamination problems, and requirement for high amounts of salt, water, land and solar irradiance have probably limited the expansion of mass cultures of this microalga The production of carotenoids from D. salina in photobioreactors has also been tested using different systems, the two most important where those developed by García-González et al. (2005) and Hejazi et al. (2004), these methods could reach higher yields than using open ponds. In Figure 15.4 different examples for the production of $D$. salina are summarized.

\section{INSERT FIGURE 15.4 NEAR HERE}

The required conditions to promote the carotenogenesis in D. salina, beyond the essential nutrients, are: high salt concentration (up to $27 \% \mathrm{NaCl}$ ) and some light stress, with photoperiod intervals of $12 \mathrm{~h}$ for 15 days. Different stress methods have also been studied and involve $\mathrm{N}$ and $\mathrm{P}$ suppression, or addition of organic non-polar biocompatible solvents. In this case, if solvent is highly non-polar, a two phase system is obtained, similar of what occurring in the method developed by Hejazi et al. (2004) which used dodecane. Results showed that $D$. salina at high light intensity remained viable over 45 days in the presence of dodecane; however, cell growth was very slow. $\beta$-carotene could be continuously extracted to the 
Cite as: Food Oxidants and Antioxidants Food Oxidants and Antioxidants: Chemical, Biological, and Functional Properties (Cap.16): 465-488 (2013), CRC Press, isbn: 9781439882412, http://hdl.handle.net/10261/109444

organic phase, while the cells continued to produce $\beta$-carotene and the extracted molecules were continuously reproduced. $\beta$-carotene extraction efficiency in this system was over $55 \%$, and productivity was much higher than that of commercial plants.

The generated $\beta$-carotene by stressing Dunaliella, is a mixture of cis and trans isomers, which has $10 \% 15$-cis- $\beta$-carotene, $41 \%$ 9-cis- $\beta$-carotene, $42 \%$ all trans- $\beta$-carotene, and $6 \%$ of other isomers and accounts for about $80 \%$ of the total carotenoids produced, being lutein the second major carotene, comprising $15 \%$ of the total carotenoids (Ribeiro et al., 2011).

After culturing, Dunaliella is commonly sold after a drying step. But there are several studies of carotenoid extraction and purification. Among them, supercritical fluid extraction could be considered as the most promising due to the high solubility of $\beta$-carotene in $\mathrm{CO}_{2}$ and the mild conditions needed thus avoiding extract degradation. Some other novel techniques have been proposed to purify carotenoids from $D$. salina with promising results, among them ultrasound-assisted extraction (Macias-Sanchez et al., 2009) and pressurized liquid extraction (Herrero et al., 2006a). The supercritical extraction process is more selective for the recovery of carotenoids than the conventional techniques since it leads to higher values for the ratio carotenoids/chlorophylls. Jaime et al. (2007) studied sub- and supercritical $\mathrm{CO}_{2}$ extraction of carotenoids from the freeze-dried D. salina. Higher yields were obtained at high pressures and low temperatures, that is, at higher $\mathrm{CO}_{2}$ densities, with optimized extraction conditions equal to $9.8{ }^{\circ} \mathrm{C}$ and 440 bar; maximum yield of $6.72 \%$, containing $52 \%$ of $\beta$-carotene were achieved. This work showed strong influence of the supercritical extraction conditions in both the $\beta$-carotene isomer composition of the extracts and the antioxidant activity measured. Statistical analysis of all the data, considering yield, antioxidant activity, and relative concentration of carotenoids in the different extracts suggested an important relationship among antioxidant activity and $\beta$-carotene isomeric relation, 9-cis/all-trans. 
Cite as: Food Oxidants and Antioxidants Food Oxidants and Antioxidants: Chemical, Biological, and Functional Properties (Cap.16): 465-488 (2013), CRC Press, isbn: 9781439882412, http://hdl.handle.net/10261/109444

The antioxidant activity of Dunaliella has been tested also in vivo. The work developed by Murthy et al. (2005) shows a clear protective role of $\beta$-carotene rich algae in the reduction of oxidative stress. Furthermore, it restores the activity of hepatic enzymes like, catalase, peroxidase and superoxide dismutase, which in turn protects vital organs against xenobiotic and other damages, results have shown a prevention of lipid oxidation mainly peroxidation to greater extent. They treated 3 groups of rats with $\mathrm{CCl}_{4}$, with $\mathrm{CCl}_{4}$ and Dunaliella and with $\mathrm{CCl}_{4}$ and synthetic $\beta$-carotene. Treatment of $\mathrm{CCl}_{4}$ decreased the activities of various antioxidant enzymes like catalase, superoxide dismutase and peroxidase. While rats pretreated with synthetic $\beta$-carotene avoided only partially the decrease on enzymatic activities, rats pretreated with Dunaliella showed no alterations in superoxide dismutase and almost no reduction in the others. These results clearly indicated the beneficial effect of algal carotenoid compared to synthetic carotene as antioxidant.

\subsection{Haematococcus pluvialis.}

Haematococcus pluvialis is an ubiquitous freshwater green microalga that is known to synthesize and accumulate esters of the red ketocarotenoid astaxanthin $\left(3,3^{\prime}\right.$-dihydroxy- $\beta, \beta-$ carotene-4,4'-dione) under stress conditions such as: nutrient deprivation, increased salinity, or light intensity (Collins et a., 2011).

Compared to other microbial sources, the green alga Haematococcus pluvialis produce the carotenoid astaxanthin in high concentrations (1.5-4.0\%). Astaxanthin is ubiquitous in nature, especially in the marine environment, it is well known because it is the responsible of the pinkish-red color of lobster, salmon and many other seafood (Lorenz and Cysewski, 2000; Grünewald et al., 2001).

The biosynthesis of astaxanthin is done through the isoprenoid pathway, like many other lipid-soluble molecules such as sterols, steroids, prostaglandins, hormones and vitamins $\mathrm{D}, \mathrm{K}$ 
Cite as: Food Oxidants and Antioxidants Food Oxidants and Antioxidants: Chemical, Biological, and Functional Properties (Cap.16): 465-488 (2013), CRC Press, isbn: 9781439882412, http://hdl.handle.net/10261/109444

and E. Haematococcus primarily contains monoesters of astaxanthin linked to 16:0, 18:1 and 18:2 fatty acids. Fatty acids are esterified onto the hydroxyl group of astaxanthin after biosynthesis of the carotenoid, which increases its solubility and stability in the cellular lipid environment (Lorenz and Cysewski, 2000). The carotenoid fraction of green vegetative cells consists mostly of lutein $(75 \%)$ and $\beta$-carotene (18\%), whereas in red cysts, astaxanthin accounts for about $80 \%$ of the whole carotenoid fraction (Grung et al., 1992).

Collins et al (2011) recently investigated carotenogenesis in living $H$. pluvialis cells using resonance-enhanced confocal Raman microscopy and multivariate curve resolution (MCR) analysis. By mathematically isolating their spectral signatures, in turn, it was possible to locate astaxanthin and $\beta$-carotene along with chlorophyll in living cells of $H$. pluvialis in various stages of the life cycle. Chlorophyll emission was found only in the chloroplast whereas astaxanthin was identified within globular and punctate regions of the cytoplasmic space. Moreover, they found evidence for $\beta$-carotene to be co-located with both the chloroplast and astaxanthin in the cytosol. These observations imply that $\beta$-carotene is a precursor for astaxanthin and the synthesis of astaxanthin occurs outside the chloroplast.

H. pluvialis can be used as a whole biomass for animal feed and food purposes, as a pigment source, and as an antioxidant agent, but for many applications astaxanthin should be extracted and purified. The main problem associated with astaxanthin extraction is its cell wall. Haematococcus has two distinct phases in its life cycle, vegetative growth phase and encysted secondary carotenoid accumulation phase. Hagen et al. (2002) studied the changes and composition of the cell wall. The motile biflagellated state exhibited a multilayered cell wall with a median tripartite crystalline layer. The transformation into the non-motile cell state was characterized by formation of a new layer, a primary wall, within the extracellular matrix. Later, a trilaminar sheath is formed inside the primary wall and the innermost and thickest part was an amorphous secondary mannan wall. 
Cite as: Food Oxidants and Antioxidants Food Oxidants and Antioxidants: Chemical, Biological, and Functional Properties (Cap.16): 465-488 (2013), CRC Press, isbn: 9781439882412, http://hdl.handle.net/10261/109444

Before extracting the asthaxanthin it is important to set up a method for cell homogenization/disruption extraction or bioavailability. Different methods have been reported for extraction of astaxanthin using solvents, treatment with extracellular enzymes followed by solvent extraction, and cell disruption processes. All these methods result in loss of pigment to some extent and are difficult to apply on a large scale. Among them those which higher yield are those developed by Sarada et al (2006) and Jaime et al. (2010). In the first one, the optimal conditions were reached using $\mathrm{HCl}$ at $70{ }^{\circ} \mathrm{C}$, cooled, centrifuged, washed with $2 \mathrm{~mL}$ of distilled water, and treated with acetone for $1 \mathrm{~h}$; this procedure shows a $90 \%$ astaxanthin extractability. Treatment time, temperature, and concentration of the acid were found to be critical factors for maximum extractability. The treatment did not affect the astaxanthin ester profile and the treated cells can be preserved until further use. Despite this method is highly interesting, it is difficult to apply on a large scale. Opposite to that, supercritical fluid extraction and pressurized liquid extraction have been proposed as useful green extraction techniques. Jaime et al (2010) pretreated the alga by freezing and mashing it with liquid nitrogen in a ceramic mortar. The process was repeated three times in order to induce cell-wall lysis. After it, astaxanthin was extracted using different pressurized solvents (PLE). The best yields were obtained with ethanol at the higher extraction temperature (200 ${ }^{\circ} \mathrm{C}$ ) while the best antioxidant activity was also achieved using ethanol but at lower temperatures $\left(50-100^{\circ} \mathrm{C}\right)$.

SFE has also been assayed to obtain astaxanthin from H.pluvialis but results were not as good as using PLE. Although astaxanthin molecule is considered containing no strong polar moieties, its large molecule inhibited its solubility in pure $\mathrm{SC}-\mathrm{CO}_{2}$ due to its low volatility, being necessary the use of co-solvents such as ethanol or vegetable oils to increase the yield extraction. Nobre et al (2006) studied the extraction of astaxanthin, astaxanthin esters and other carotenoids from $H$. pluvialis using supercritical $\mathrm{CO}_{2}$, in order to evaluate the best 
Cite as: Food Oxidants and Antioxidants Food Oxidants and Antioxidants: Chemical, Biological, and Functional Properties (Cap.16): 465-488 (2013), CRC Press, isbn: 9781439882412, http://hdl.handle.net/10261/109444

extraction conditions. The best recovery was achieved at 300 bar, $60{ }^{\circ} \mathrm{C}$ and $10 \%$ ethanol; under these condition all the carotenoids present in $H$. pluvialis (lutein, astaxanthin, $\beta$ carotene) were extracted with values higher than $90 \%$ (see figure 15.5 ), with the exception of canthaxanthin (about 85\%).

\section{INSERT FIGURE 15.5 NEAR HERE}

The antioxidant activity of $H$. pluvialis extracts has been measured using several methods. In the cited work published by Jaime et al (2010), $\operatorname{ABTS}^{\cdot+}$ (2,2-azinobis-3-ethylbenzothiazoline-6-sulfonic acid) was used to measure the radical scavenging activity. In general, ethanol extracts presented better antioxidant activity than hexane extracts at all temperatures tested. Antioxidant activity of $H$. pluvialis extracts seemed to be related to their free carotenoids' content, which exists in more concentration in green cells showing higher TEAC values than red cells. Results demonstrated that the antioxidant activity of red cells' extracts could be greatly improved after hydrolysis of the mono- and diesters of astaxanthin, reaction that seems to occur after ingestion of these products. Other authors used $\mathrm{DPPH}^{\circ}$ (diphenylpicrylhydrazyl) to measure the antioxidant activity. $\mathrm{DPPH}^{\bullet}$ shows a maximum of absorption at $482 \mathrm{~nm}$ and other at $517 \mathrm{~nm}$, and therefore a clear interference with unreacted astaxanthin can be expected when measuring the antioxidant activities using this methodology.

\section{CONCLUSIONS.}


Cite as: Food Oxidants and Antioxidants Food Oxidants and Antioxidants: Chemical, Biological, and Functional Properties (Cap.16): 465-488 (2013), CRC Press, isbn: 9781439882412, http://hdl.handle.net/10261/109444

\section{REFERENCES.}

Albu, S., Joyce, E., Paniwnyk, L., Lorimer, J. P., Mason, T. J. 2004. Potential for the use of ultrasound in the extraction of antioxidants from Rosmarinus officinalis for the food and pharmaceutical industry. Ultrason. Sonochem. 11:261-265.

Anadon, A., Martinez-Larranaga, M. R., Martinez, M. A., Ares, I., Garcia-Risco, M. R., Senorans, F. J., Reglero, G. 2008. Acute oral safety study of rosemary extracts in rats. J. Food Prot. 71:790-795.

Anastas, P. T., Zimmerman, J. B. 2003. Design through the twelve principles of green engineering. Environ. Sci. Technol. 37:94A-101A.

Aruoma, O. I., Halliwell, B., Aeschbach, R., Loliger, J. 1992. Antioxidant and pro-oxidant properties of active rosemary constituents: carnosol and carnosic acid. Xenobiotica 22:257268.

Babovic, N., Djilas, S., Jadranin, M., Vajs, V., Ivanovic, J., Petrovic, S., Zizovic, I. 2010. Supercritical carbon dioxide extraction of antioxidant fractions from selected Lamiaceae herbs and their antioxidant capacity. Inn. Food Sci. Emerg. Technol. 11:98-107.

Basaga, H., Tekkaya, C., Acikel, F. 1997. Antioxidative and free radical scavenging properties of rosemary extract. Lebens. Wissen. Technol. 30:105-108.

Boyle, T. H., Craker, L. E., Simon, J. E. 1991. Growing medium and fertilization regime influence growth and essential oil content of rosemary. Hort. Sci. 26:33-34.

Braida, I., Mattea, M., Cardarelli, D. 2008. Extraction-adsorption-desorption process under supercritical condition as a method to concentrate antioxidants from natural sources. $J$. Supercrit. Fluids 45:195-199.

Brieskorn, C., Fuchs, A., Bredenberg, J. B., McChesney, J. E. W. 1964. The structure of carnosol. J. Org. Chem. 29:2293-2298. 
Cite as: Food Oxidants and Antioxidants Food Oxidants and Antioxidants: Chemical, Biological, and Functional Properties (Cap.16): 465-488 (2013), CRC Press, isbn: 9781439882412, http://hdl.handle.net/10261/109444

Brigelius-Flohe, R., Kelly, F.J., Salonen, J.T., Neuzil, J., Zingg, J-M, Azzi, A. 2002. The European perspective on vitamin E: current knowledge and future research. Am. J. Clin. Nutr. $76: 703-716$.

Carvalho, R. N., Moura, L. S., Rosa, P. T. V., Meireles, M. A. A. 2005. Supercritical fluid extraction from rosemary (Rosmarinus officinalis): Kinetic data, extract's global yield, composition, and antioxidant activity. J. Supercrit. Fluids 35:197-204.

Cavero, S., Jaime, L., Martin-Alvarez, P. J., Señorans, F. J., Reglero, G., Ibañez, E. 2005. In vitro antioxidant analysis of supercritical fluid extracts from rosemary (Rosmarinus officinalis L.). Eur. Food Res. Technol. 221:478-486.

Celiktas, O. Y., Bedir, E., Sukan, F. V. 2007. In vitro antioxidant activities of Rosmarinus officinalis extracts treated with supercritical carbon dioxide. Food Chem. 101:1457-1464.

Chalchat, J. C., Garry, R. P., Michet, A., Benjilali, B., Chabart, J. L. 1993. Essential oils of rosemary (Rosmarinus officinalis L.). The chemical composition of oils of various origins (Morocco, Spain, France). J. Essent. Oil Res. 5:613-618.

Chang, C. H., Chyau, C. C., Hsieh, C. L., Wu, Y. Y., Ker, Y. B., Tsen, H. Y., Peng, R. Y. 2008. Relevance of phenolic diterpene constituents to antioxidant activity of supercritical $\mathrm{CO}_{2}$ extract from the leaves of rosemary. Nat. Prod. Res. 22:76-90.

Collins, A. M., Jones, H. D. T., Han, D., Hu, Q., Beechem, T. E., Timlin, J. A. 2011. Carotenoid distribution in living cells of Haematococcus pluvialis (chlorophyceae). PLoS ONE 6:e24302.

Crego, A. L., Ibañez, E., Garcia, E., De Pablos, R. R., Senorans, F. J., Reglero, G., Cifuentes, A. 2004. Capillary electrophoresis separation of rosemary antioxidants from subcritical water extracts. Eur. Food Res. Technol. 219:549-555. 
Cite as: Food Oxidants and Antioxidants Food Oxidants and Antioxidants: Chemical, Biological, and Functional Properties (Cap.16): 465-488 (2013), CRC Press, isbn: 9781439882412, http://hdl.handle.net/10261/109444

Cuvelier, M. E., Richard, H., Berset, C. 1996. Antioxidative activity and phenolic composition of pilot-plant and commercial extracts of sage and rosemary. J. Am Oil Chem. Soc. 73:645-652.

Dufossé, L., Galaup, P., Yaron, A., Arad, S. M., Blanc, P., Murthy, K. N. C., et al. 2005. Microorganisms and microalgae as sources of pigments for food use: a scientific oddity or an industrial reality? Trends Food Sci. Technol. 16:389-406.

Frankel, E. N., Shu, W. H., Aeschbatch, R., Prior, E. 1996. Antioxidant activity of a rosemary extract and its constituents carnosic acid, carnosol, and rosmarinic acid in bulk oil and oil-inwater emulsion. J. Agric. Food Chem. 44:131-135.

Ganzler, K., Salgó, A., Valkó, K. 1986. Microwave extraction: A novel sample preparation method for chromatography. J. Chromatogr A. 371:299-306.

García-González, M., Moreno, J., Manzano, J. C., Florencio, F. J., Guerrero, M. G. 2005. Production of Dunalliela salina biomass rich in 9-cis- $\beta$-carotene and lutein in a closed tubular photobioreactor. J. Biotechnol. 115:81-90.

Garcia-Risco, M. R., Hernandez, E. J., Vicente, G., Fornari, T., Señorans, F. J., Reglero, G. 2011. Kinetic study of pilot-scale supercritical $\mathrm{CO}_{2}$ extraction of rosemary (Rosmarinus officinalis) leaves. J. Supercrit. Fluids 55:971-976.

Grünewald, K., Hirschberg, J., Hagen, C. 2001. Ketocarotenoid biosynthesis outside of plastids in the unicellular green alga Haematococcus pluvialis. J. Biol. Chem. 276:6023-6029. Grung, M., D'Souza, F.M.L., Borowitzka, M., Liaaen-Jensen, S. 1992. Haematococcus pluvialis aplanospores as a source of (3 S, 3'S)-astaxanthin esters. J. Appl. Phycol. 4:165-171. Guedes, C. A., Amaro, H. M., Malcata, F. X. 2011. Microalgae as sources of high addedvalue compounds - a brief review of recent work. Biotechnol. Progress 27:597-613.

Guillén, M. D., Cabo, N., Burillo, J. 1996. Characterisation of the essential oils of some cultivated aromatic plants of industrial interest. J. Sci. Food Agric. 70:359-363. 
Cite as: Food Oxidants and Antioxidants Food Oxidants and Antioxidants: Chemical, Biological, and Functional Properties (Cap.16): 465-488 (2013), CRC Press, isbn: 9781439882412, http://hdl.handle.net/10261/109444

Hadolin, M., Rizner Hras, A., Bauman, D., Knez, Z. 2004. Isolation and concentration of natural antioxidants with high-pressure extraction. Inn. Food Sci. Emerg. Technol. 5:245-248. Hagen, C., Siegmund, S., Braune, W. 2002. Ultrastructural and chemical changes in the cell wall of Haematococcus pluvialis (Volvocales, Chlorophyta) during aplanospore formation. Eur. J. Phycol. 37;217-226.

Haraguchi, H., Saito, T., Okamura, N., Yagi, A. 1995. Inhibition of lipid peroxidation and superoxide generation by diterpenoids from Rosmarinus officinalis. Planta Medica 61:333336.

Harris, A., Devaraj, S., Jialal, I. 2002. Oxidative stress, alpha-tocopherol therapy, and atherosclerosis. Curr. Atheroscler. Rep. 4:373-380.

Hejazi, M. A., Holwerda, E., Wijffels, R. H. 2004. Milking microalga Dunaliella salina for $\beta$ carotene production in two-phase bioreactors. Biotechnol Bioeng. 85:475-481.

Herrero, M., Arraez-Roman, D., Segura, A., Kenndler, E., Gius, B., Raggi, M. A., Ibanez, E., Cifuentes, A. 2005b. Pressurized liquid extraction-capillary electrophoresis-mass spectrometry for the analysis of polar antioxidants in rosemary extracts. J. Chromatogr. A 1084:54-62.

Herrero, M., Cifuentes, A., Ibáñez, E. 2006a. Sub- and supercritical fluid extraction of functional ingredients from different natural sources: Plants, food-by-products, algae and microalgae: A review. Food Chem. 98:136-148.

Herrero, M., Jaime, L., Martin-Alvarez, P. J., Cifuentes, A., Ibanez, E. 2006b . Optimization of the extraction of antioxidants from Dunaliella salina microalga by pressurized liquids $J$. Agric. Food Chem. 54:5597-5603.

Herrero, M., Martín-Álvarez, P.J., Señoráns, F.J., Cifuentes, A., Ibáñez, E. 2005a. Optimization of accelerated solvent extraction of antioxidants from Spirulina platensis microalga. Food Chem. 93:417-423. 
Cite as: Food Oxidants and Antioxidants Food Oxidants and Antioxidants: Chemical, Biological, and Functional Properties (Cap.16): 465-488 (2013), CRC Press, isbn: 9781439882412, http://hdl.handle.net/10261/109444

Herrero, M., Plaza, M., Cifuentes, A., Ibanez, E. 2010. Green processes for the extraction of bioactives from Rosemary: Chemical and functional characterization via ultra-performance liquid chromatography-tandem mass spectrometry and in-vitro assays. J. Chromatogr. A $1217: 2512-2520$.

Hidalgo, P. J., Ubera, J. L., Tena, M. T., Valcárcel, M. 1998. Determination of the carnosic acid content in wild and cultivated Rosmarinus officinalis. J. Agric. Food Chem. 46:26242627.

Hopia, A., Shu, W., Schwartz, K., German, J., Frankel, E. 1996. Effect of different lipid systems on antioxidant activity of rosemary constituents carnosol and carnosic acid with and without alpha-tocopherol. J. Agric. Food Chem. 44:2030-2036.

Hosikian, A., Lim, S., Halim, R., Danquah, M. K. 2010. Chlorophyll extraction from microalgae: a review on the process engineering aspects. Int. J. Chem. Eng. Article ID 391632.

Houlihan, C., Ho, C., Chang, S. 1984. Elucidation of the chemical structure of a novel antioxidant, rosmaridiphenol, isolated from rosemary. J. Am Oil Chem. Soc. 61:1036-1039.

Houlihan, C., Ho, C., Chang, S. 1985. The structure of rosmariquinone. A new antioxidant isolated from Rosmarinus officinalis L. J. Am Oil Chem. Soc. 62:96-98.

Hosseini Tafresi, A., Shariati, M. 2009. Dunaliella biotechnology: methods and applications. J. Appl. Microbiol. 107:14-35.

Ibáñez, E., Cifuentes, A., Rodríguez-Meizoso, I., Mendiola, J.A., Reglero, G., Señoráns, F.J., Turner, C. 2009. Device and procedure for the on-line extraction and drying of complex extracts. Patent: P200900164.

Ibañez, E., Kubatova, A., Senorans, F.J., Cavero, S., Reglero, G., Hawthorne, S. B. 2003. Subcritical water extraction of antioxidant compounds from rosemary plants. J. Agric. Food Chem. 51:375-382. 
Cite as: Food Oxidants and Antioxidants Food Oxidants and Antioxidants: Chemical, Biological, and Functional Properties (Cap.16): 465-488 (2013), CRC Press, isbn: 9781439882412, http://hdl.handle.net/10261/109444

Ibañez, E., Oca, A., De Murga, G., Lopez-Sebastian, S., Tabera, J., Reglero, G. 1999. Supercritical fluid extraction and fractionation of different preprocessed rosemary plants. $J$. Agric. Food Chem. 47:1400-1404.

Inatani, R., Nakatani, N., Fuwa, H., Seto, H. 1982. Structure of a new antioxidative phenolic diterpene isolated from rosemary. Agric. Biol. Chem. 46:1661-1666.

Inatani, R., Nakatani, N., Fuwa, H.1983. Antioxidative effect of the constituents of rosemary and their derivatives. Agric. Biol. Chem. 47:521-528.

Jaime, L., Mendiola, J. A., Ibáñez, E., Martin-Álvarez, P. J., Cifuentes, A., Reglero, G., Señoráns, F. J. 2007. $\beta$-Carotene isomer composition of sub- and supercritical carbon dioxide extracts. Antioxidant activity measurement. J. Agric. Food Chem. 55:10585-10590.

Jaime, L., Rodríguez-Meizoso, I., Cifuentes, A., Santoyo, S., Suarez, S., Ibáñez, E., Señorans, F.J. 2010. Pressurized liquids as an alternative process to antioxidant carotenoids' extraction from Haematococcus pluvialis microalgae. LWT - Food Sci. Technol. 43:105-112.

Kuo, C. F., Su, J. D., Chiu, C. H., Peng, C. C., Chang, C. H., Sung, T. Y., Huang, S. H., Lee, W. C., Chyau, C. C. 2011. Anti-inflammatory effects of supercritical carbon dioxide extract and its isolated carnosic acid from rosmarinus officinalis leaves. J. Agric. Food Chem. 59:3674-3685.

Leal, P. F., Braga, M. E. M., Sato, D. N., Carvalho, J. E., Marques, M. O. M., Meireles, M. A. A. 2003. Functional properties of spice extracts obtained via supercritical fluid extraction. $J$. Agric. Food Chem. 51:2520-2525.

Lopez-Sebastian, S., Ramos, E., Ibanez, E., Bueno, J. M., Ballester, L., Tabera, J., Reglero, G. 1998. Dearomatization of antioxidant rosemary extracts by treatment with supercritical carbon dioxide. J. Agric.Food Chem. 46:13-19.

Lorenz, R. T., Cysewski G. R. 2000. Commercial potential for Haematococcus microalgae as a natural source of astaxanthin. Trends Biotechnol. 18:160-167. 
Cite as: Food Oxidants and Antioxidants Food Oxidants and Antioxidants: Chemical, Biological, and Functional Properties (Cap.16): 465-488 (2013), CRC Press, isbn: 9781439882412, http://hdl.handle.net/10261/109444

Luis, J. G. 1991. Chemistry, biogenesis, and chemotaxonomy of the diterpenoids of Salvia. . In: Ecological Chemistry and Biochemistry of Plant Terpenoids. Ed., J.B. Harborne and F. A. Tomas-Barberan. Oxford: Clarendon Press.

Luis, J. G., Quiñones, W., Grillo, T. A., Kishi, M. P. 1994. Diterpenes from the aerial part of Salvia columbariae. Phytochem. 35:1373-1374.

Macías-Sánchez, M. D., Mantell, C., Rodríguez, M., Martínez de la Ossa, E., Lubián, L. M., Montero, O. 2009. Comparison of supercritical fluid and ultrasound-assisted extraction of carotenoids and chlorophyll a from Dunaliella salina. Talanta 77:948-952.

Mendiola, J. A., Herrero, M., Cifuentes, A., Ibáñez, E. 2007. Use of compressed fluids for sample preparation: Food applications. J. Chromatogr. A. 1152:234-246.

Mizrahi, I., Juarez, M. A., Bandoni, A. L. 1991. The essential oil of Rosmarinus officinalis growing in Argentina. J. Essent. Oil Res. 3:11-15.

Munné-Bosch, S., Alegre, L., Schwarz, K. 2000. The formation of phenolic diterpenes in Rosmarinus officinalis L. under Mediterranean climate. Eur. Food Res. Technol. 210:263267.

Murthy, K. N. C., Vanitha, A., Rajesha, J., Swamy, M. M., Sowmya, P. R., Ravishankar, G. A. 2005. In vivo antioxidant activity of carotenoids from Dunaliella salina - A green microalga. Life Sci. 76:1381-1390.

Nakatani, N., Inatani, R. 1984. Two antioxidative diterpenes from rosemary and a revised structure for rosmanol. Agric. Biol. Chem. 48:2081-2085.

National Institute for Health, N.H.I. (2002). National Institute for Health. Facts about Dietary Suplements-Vitamin E. Maryland: Warren Grant Magnuson Clinical Center.

Navarrete, A., Herrero, M., Martin, A., Cocero, M. J., Ibañez, E. Valorization of solid wastes from essential oil industry. J. Food Eng. 104:196-201. 
Cite as: Food Oxidants and Antioxidants Food Oxidants and Antioxidants: Chemical, Biological, and Functional Properties (Cap.16): 465-488 (2013), CRC Press, isbn: 9781439882412, http://hdl.handle.net/10261/109444

Nieto, A., Borrull, F., Pocurull, E., Marcé, R. M. 2010. Pressurized liquid extraction: A useful technique to extract pharmaceuticals and personal-care products from sewage sludge, $\operatorname{Tr} A C$ Trends Anal. Chem. 29:752-764.

Nobre, B., Marcelo, F., Passos, R., Beirão, L., Palavra, A., Gouveia, L., Mendes, R. 2006. Supercritical carbon dioxide extraction of astaxanthin and other carotenoids from the microalga Haematococcus pluvialis. Eur. Food Res. Technol. 223:787-790.

Okamura, N., Fujimoto, Y., Kuwabara, S., Yagi, A. 1994. High-performance liquid chromatographic determination of carnosic acid and carnosol in Rosmarinus officinalis and Salvia officinalis. J. Chromatogr. A 679:381-386.

Okoh, O. O., Sadimenko, A. P., Afolayan, A. J. 2011. Antioxidant activities of Rosmarinus officinalis L. essential oil obtained by hydro-distillation and solvent free microwave extraction. African J. Biotechnol. 10:4207-4211.

Ötles S. 2009. Handbook of Food Analysis Instruments. 1st ed. Boca Raton: CRC Press Taylor \& Francis Group.

Palozza, P., Simone, R., Mele, M.C. 2008. Interplay of carotenoids with cigarette smoking: Implications in lung cancer. Curr. Med. Chem. 15:844-854.

Plaza, M., Amigo-Benavent, M., del Castillo, M. D., Ibañez, E., Herrero, M. 2010. Facts about the formation of new antioxidants in natural samples after subcritical water extraction. Food Res. Int. 43:2341-2348.

Posadas, S. J., Caz, V., Largo, C., De la Gandara, B., Matallanas, B., Reglero, G., De Miguel, E. 2009. Protective effect of supercritical fluid rosemary extract, Rosmarinus officinalis, on antioxidants of major organs of aged rats. Exp. Gerontol. 44:383-389.

Rac, M., Ostric-Matijasevic, B. 1955. The properties of rosemary as an antioxidant. Rev. Fr. Corps. Gras. 2:796. 
Cite as: Food Oxidants and Antioxidants Food Oxidants and Antioxidants: Chemical, Biological, and Functional Properties (Cap.16): 465-488 (2013), CRC Press, isbn: 9781439882412, http://hdl.handle.net/10261/109444

Ramirez, P., Fornari, T., Señorans, F.J., Ibañez, E., Reglero, G. 2005. Isolation of phenolic antioxidant compounds by SFC. J. Supercrit. Fluids 35:128-132.

Ramirez, P., Garcia-Risco, M. R., Santoyo, S., Senorans, F. J., Ibanez, E., Reglero, G. 2006. Isolation of functional ingredients from rosemary by preparative-supercritical fluid chromatography (Prep-SFC). J. Pharm. Biomed. Anal. 41:1606-1613.

Ramirez, P., Santoyo, S., Garcia-Risco, M. R., Senorans, F. J., Ibanez, E., Reglero, G.2007. Use of specially designed columns for antioxidants and antimicrobials enrichment by preparative supercritical fluid chromatography. J. Chromatogr. A 114:234-242.

Ramirez, P., Señorans, F. J., Ibanez, E., Reglero, G. 2004. Separation of rosemary antioxidant compounds by supercritical fluid chromatography on coated packed capillary columns. $J$. Chromatogr. A, 1057: 241-245.

Ribeiro, B. D., Barreto, D. W., Coelho, M. A. Z. 2011. Technological aspects of $\beta$-carotene production. Food Bioproc. Technol. 4:693-701.

Richhelmer, S. L., Bailey, D. T., Bernart, M. W., Kent, M., Vininski, J. V., Anderson, L. D. 1999. Antioxidant activity and oxidative degradation of phenolic compounds isolated from rosemary. Recent Res. Develop. Oil Chem. 3:45-58.

Richter, B. E., Jones, B. A., Ezzell, J. L., Porter, N. L., Avdalovic, N., Pohl, C. 1996. Accelerated solvent extraction: A technique for sample preparation. Anal. Chem. 68:10331039.

Sarada, R., Vidhyavathi, R., Usha, D., Ravishankar, G. A. 2006. An efficient method for extraction of astaxanthin from green alga Haematococcus pluvialis. J. Agric. Food Chem. $54: 7585-7588$.

Schaich, K. M. 2006. Developing a rational basis for selection of antioxidant screening and testing methods. Acta Hort. 709:79-94. 
Cite as: Food Oxidants and Antioxidants Food Oxidants and Antioxidants: Chemical, Biological, and Functional Properties (Cap.16): 465-488 (2013), CRC Press, isbn: 9781439882412, http://hdl.handle.net/10261/109444

Schubert, N., García-Mendoza, E., Pacheco-Ruiz, I. 2006. Carotenoid composition of marine algae. J. Phycol. 42:1208-1216.

Schwarz, K., Ternes, W. 1992. Antioxidative constituents of Rosmarinus officinalis and Salvia officinalis II. Isolation of carnosic acid and formation of other phenolic diterpenes. $Z$. Lebensm. Unters. Forsch. 195:99-103.

Señorans, F. J., Ibañez, E., Cavero, S., Tabera, J., Reglero G. 2000. Liquid chromatographicmass spectrometric analysis of supercritical-fluid extracts of rosemary plants. J. Chromatogr. A 870:491-499.

Singletary, K. W., Rokusek, J. T. 1997. Tissue specific enhancement of xenobiotic detoxification enzymes in mice by dietary rosemary extract. Plant Foods Human Nutr. 50:4753.

Soler-Rivas, C., Marin, F. R., Santoyo, S., Garcia-Risco, M. R., Senorans, J., Reglero, G. 2010. Testing and enhancing the in vitro bioaccessibility and bioavailability of Rosmarinus officinalis extracts with a high level of antioxidant abietanes. J. Agric. Food Chem. 58:11441152.

Tena, M. T., Valcarcel, M., Hidalgo, P. J., Ubera, J. L. 1997. Supercritical Fluid Extraction of natural antioxidants from rosemary: comparison with liquid solvent sonication. Anal. Chem. 69:521-526.

Topal, U., Sasaki, M., Goto, M., Otles, S. 2008. Chemical compositions and antioxidant properties of essential oils from nine species of Turkish plants obtained by supercritical carbon dioxide extraction and steam distillation. Int. J. Food Sci. Nutr. 59:619-634.

Turner, C., Ibañez, E. 2012. Pressurized hot water extraction, In: Enhancing extraction processes in the food industry, ed. Labovka, Vorobiev \& Chemat. Boca-Raton: CRC Press. 
Cite as: Food Oxidants and Antioxidants Food Oxidants and Antioxidants: Chemical, Biological, and Functional Properties (Cap.16): 465-488 (2013), CRC Press, isbn: 9781439882412, http://hdl.handle.net/10261/109444

Visentin, A., Cismondi, M., Maestri, D. 2011. Supercritical $\mathrm{CO}_{2}$ fractionation of rosemary ethanolic oleoresins as a method to improve carnosic acid recovery. Inn. Food Sci. Emerg. Technol. 12:142-145.

Wada, S., Fang, X. 1992. The synergistic antioxidant effects of rosemary extract and atocopherol in sardine oil model system and frozen-crushed fish meat. J. Food Proc. Pres. $16: 263-274$.

Wu, J., Lee, M., Ho C. T., Chang, S. S. 1982. Elucidation of the chemical structures of natural antioxidants isolated from Rosemary. J. Am Oil Chem. Soc. 59:339-345. 
Cite as: Food Oxidants and Antioxidants Food Oxidants and Antioxidants: Chemical, Biological, and Functional Properties (Cap.16): 465-488 (2013), CRC Press, isbn: 9781439882412, http://hdl.handle.net/10261/109444

\section{FIGURE LEGENDS}

Figure 15.1. Multiple-purpose extraction device scheme that could be used for SFE, PLE or SWE. Liquid solvents (1); pump for liquids (2); $\mathrm{CO}_{2}$ pump (3); on/off valves (4); check valves (5); preheating bath (6); oven and extraction cell (7); micrometering valve (8); extract collector (9); additional extract separator (10).

Figure 15.2. Chemical structures of some of the most important antioxidants found in Rosmarinus officinalis.

Figure 15.3. Schematic diagram of the experimental set-up employed for the extractionadsorption-desorption procedure. Reproduced with permission from Braida et al. (2008).

Figure 15.4. Flow chart of culturing and processing of Dunaliella salina in different culture systems. Reproduced with permission from Hosseini Tafresi and Shariati (2009).

Figure 15.5. Recovery of total astaxanthin as a function of $\mathrm{CO}_{2}$ amount with (a) and without $(\diamond)$ ethanol as a co-solvent, and $\mathrm{CO}_{2}$ with ethanol doubling the initial sample crushing time

( $\Delta$ ) at $60^{\circ} \mathrm{C}$ and 300 bar. Reproduced with permission from Nobre et al. (2006). 


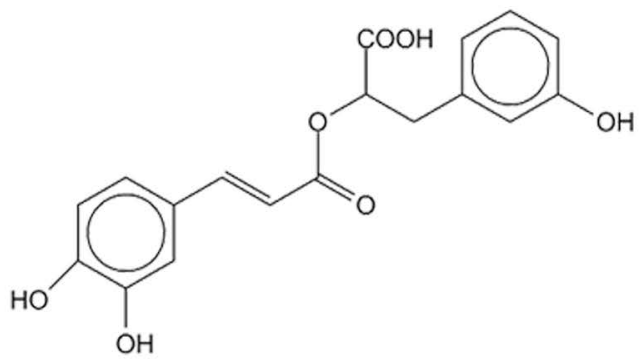

Rosmarinic acid

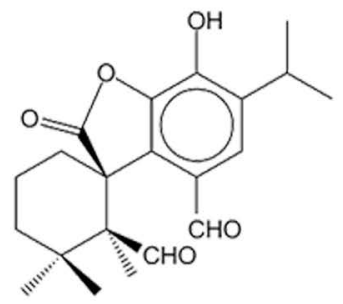

Rosmadial

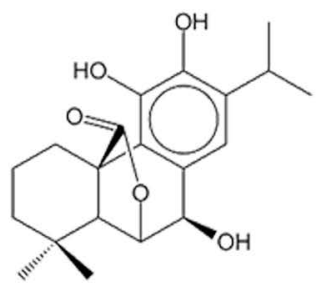

Epirosmanol

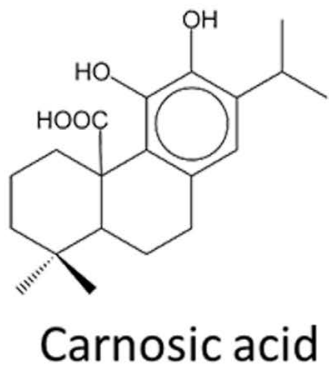




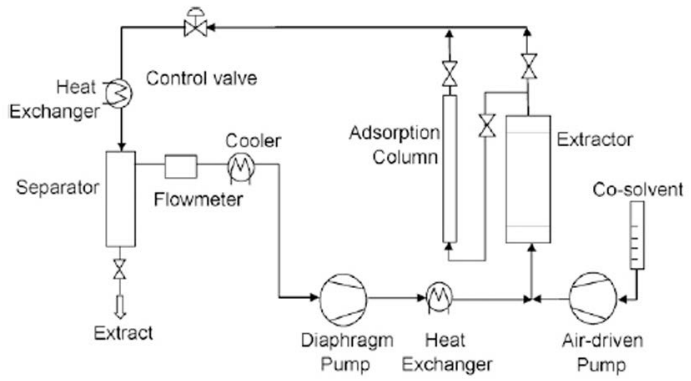




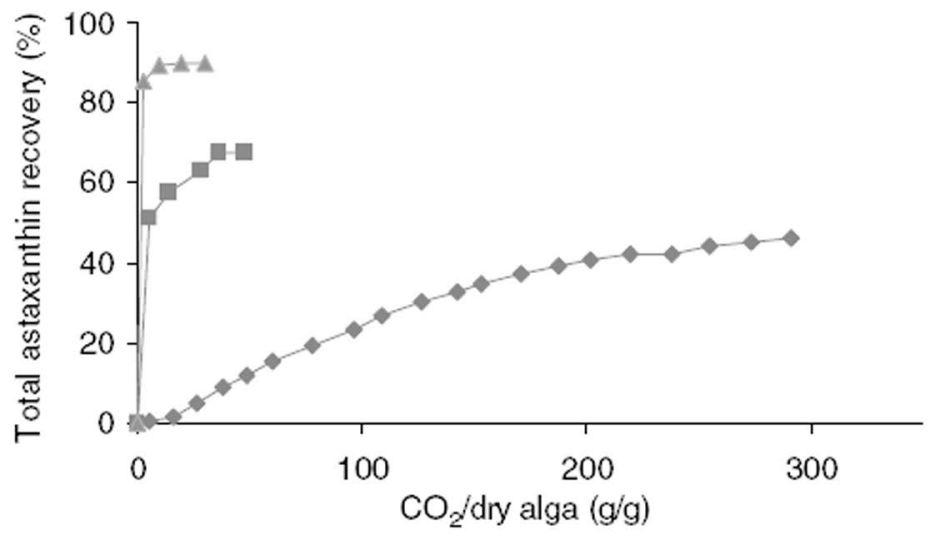

